\title{
Nós, os de lá, estamos cá: reflexões sobre a educação escolar quilombola no contexto dos impedimentos à co-presença
}

\author{
Evanilson Tavares de França ${ }^{1}$ \\ Jackeline Rodrigues Mendes ${ }^{2}$
}

\begin{abstract}
Resumo
A educação sempre compôs a pauta de luta dos movimentos negros no Brasil. Ainda assim, a LDB 9394/96 fez-se muda em relação à educação das comunidades quilombolas, lacuna somente preenchida, após 16 anos, por via da Resolução CNE/CEB n.ㅇ 08/2012. Não obstante, as pesquisas desenvolvidas em quilombos revelam a ausência de diálogo entre as práticas culturais das escolas neles localizadas e a contextura sociocultural. À vista disso, o presente artigo objetiva pensar as razões que subjazem e fundamentam as práticas curriculares excludentes (invisibilizadoras) naqueles territórios. Para tanto, dialogaremos com Fanon, Santos e outros. Esperamos que as discussões aqui implementadas possam contribuir para a ressignificação dos pensares e fazeres e para a construção de um currículo intercultural.
\end{abstract}

Palavras-chave: Quilombo; Educação escolar Quilombola; Práticas curriculares; Práticas culturais.

We, from there, are here: reflections about quilombola education in the context of impediments to co-presence

\section{Abstract}

The Normative Resolution No. 08/2012, issued by the National Education Council of Brazil (CNE/CEB n.ㅇ 08/2012), fills a gap left by the Law of Directives and Bases of National Education (LDB 9394/1996) with regards to school education for Quilombolas people. Nonetheless, studies undertaken in Quilombos have revealed a lack of dialogue between school cultural practices and the sociocultural context where such communities find themselves. From this point of view, this article aims to promote reflections/discussions about reasons which underlie and give basis to curricular practices that cause exclusion (or invisibilization) in the above-mentioned territories. For this purpose, we will resort to Fanon, Santos and others. We hope these discussions will be of some use to the resignification of ideas and practices as well as the construction of an intercultural curriculum.

Keywords: Quilombo; School education; Quilombola; Curricular practices; Cultural practices.

\section{Considerações iniciais}

E então... "Nós, os de lá, estamos cá: [...]". Não, não somos quilombolas - não se considerarmos o entendimento constitucional de remanescentes das comunidades dos quilombos expresso na Constituição Federal de 1988 (BRASIL, 2017, Art. 68): aquela Carta Magna vincula essas singularidades à ocupação, na atualidade, de terras específicas (regiões que abrigaram negras e negros que bravamente resistiram ao processo escravocrata, permeado pela

\footnotetext{
${ }^{1}$ Doutorando em Educação pela Universidade Estadual de Campinas (Unicamp), Campinas, evanilsont@gmail.com.

2 Docente PPGE-FE-Universidade Estadual de Campinas (Unicamp), Campinas, jamendes@unicamp.br.
}

Periódico Horizontes - USF - Itatiba, SP - Brasil - e019034 


\section{H O R I Z O N T E S}

DOI: https://doi.org/10.24933/horizontes.v37i0.669

negação do outro) durante os quase quatrocentos anos de escravização (oficial) de africanos e africanas (e seus descendentes) em terras brasilis. Também não somos quilombolas se considerarmos a delimitação estabelecida pela Associação Brasileira de Antropologia (ABA), para a qual, segundo Arruti:

A categoria "remanescentes de quilombos" deve compreender todos os grupos que desenvolveram práticas de resistência na manutenção e na reprodução de seus modos de vida característicos em um determinado lugar, cuja identidade se define por uma referência histórica comum, construída a partir de vivências e de valores partilhados. Nesse sentido, eles se constituem como "grupos étnicos", isto é, um tipo organizacional que confere pertencimento através de normas e meios empregados para indicar afiliação ou exclusão, cuja territorialidade é caracterizada pelo "uso comum", pela "sazonalidade das atividades agrícolas, extrativistas e outras e por uma ocupação do espaço que teria por base os laços de parentesco e vizinhança, assentados em relações de solidariedade e reciprocidade" (ARRUTI, 2017, p.113, grifo nosso).

Para o Decreto 4.887 (BRASIL, 2003b), que "regulamenta o procedimento para identificação, reconhecimento, delimitação, demarcação e titulação das terras ocupadas por remanescentes das comunidades dos quilombos de que trata o art. 68 do Ato das Disposições Constitucionais Transitórias", remanescentes de quilombos são "[...] os grupos étnico-raciais, segundo critérios de auto-atribuição, com trajetória histórica própria, dotados de relações territoriais específicas, com presunção de ancestralidade negra relacionada com a resistência à opressão histórica sofrida" (BRASIL, 2003b, Art. 2º, grifo nossos). Arruti (2017) reforça que a associação entre quilombo e território "é reivindicada em diversos textos de reflexão e de sistematização jurídica" (p.113). Por via disso, considerando também aquele documento, não, não somos quilombolas.

Então... "Nós, os de lá, estamos cá: reflexões sobre a educação escolar quilombola no contexto dos impedimentos à co-presença", artigo escrito por não-quilombolas(?), insere-se na compreensão fanoniana, segundo a qual "todas as vezes em que um homem fizer triunfar a dignidade do espírito, todas as vezes em que um homem disser não a qualquer tentativa de opressão do seu semelhante, sinto-me solidário com seu ato" (FANON, 2008, p.187). Nesse sentido, somos todos (os que se indignam) quilombolas fora das fronteiras, somos todos quilombolas não o sendo - somos quilombolas não categorizados. Ou ainda: "Sou preto, e 
toneladas de grilhões, tempestades de pancada, torrentes de escarro escorrem pelas minhas costas" (FANON, 2008, p. 190) e também pelas costas de homens e de mulheres que se inscrevem nas lutas de resistência, em suas diversas formas e modalidades, contra o erguimento de um mundo que exclui, que marginaliza, que mata - pelo abandono, pela fome, pela negação, pela invisibilização. Nesse outro sentido, também somos todos (os que se indignam) quilombolas.

Somos também, todos (os que se indignam), quilombolas porque, como lembra Solano Trindade, "[...] os negros oprimidos / escravizados / em luta por liberdade / são meus irmãos / Para estes tenho um poema / grande como o Nilo" (2007). E a poesia, em dores ou flores, pode ser cantada por todos, por qualquer um, independentemente da cor da pele ou da filiação étnicoracial, bastando, para tanto, que as estúpidas armas, materiais e/ou simbólicas, que promovem a invisibilização ou a negação do outro também lhe cortem a carne. A ideia é que nos posicionemos, todos (quilombolas por direito ou por indignação), nas trincheiras de combate às injustiças sociais.

À guisa disso, e a partir do entendimento de que as barreiras que separam nós e eles precisam ser demolidas - mesmo porque esses afastamentos e/ou negações resultam de construções histórico-sociais (FANON, 2008) -, propomo-nos aqui, mobilizados por nossa indignação, discutir a Educação Escolar Quilombola, mas advogando a continuidade da multiplicação dessa voz e a presença robusta das vozes quilombolas nessa multiplicidade. No atual cenário, considerando nomeadamente (mas não só) nossas investigações na Comunidade Quilombola Mussuca (localizada em Sergipe - Brasil), essa continuidade não vem se efetivando ou, quando e se o faz, a timidez Ihe é companheira. Conforme incursões investigativas de França (2013), o projeto político-pedagógico da escola municipal, localizada naquela comunidade negra, fora elaborado por uma consultoria contratada pela Secretaria Municipal de Educação (SEMED), sem contar, portanto, com a participação de professores, estudantes e demais moradores do quilombo.

Convém negritar ainda que, antes mesmo de sermos todos quilombolas (referimo-nos àqueles e àquelas que se indignam), somos homens e mulheres que buscam construir suas vidas a partir do reconhecimento de que as relações humanas estão profundamente atravessadas pelo poder (GALLO, 2005) e as tensões que demarcam tais relações exigem, para reconfiguração Periódico Horizontes - USF - Itatiba, SP - Brasil - e019034 
desse cenário (um cenário que exclui), um melhor conhecimento do outro, um melhor conhecimento com o outro e o reconhecimento de que o encontro dos conhecimentos pode alargar o presente e encurtar o futuro, como espera Boaventura de Sousa Santos (2007), o que, parece-nos, constrói certo diálogo com a preocupação esboçada por Grossberg:

Temos que entender como e por que as sociedades continuam a produzir todas as formas de desumanidade, desigualdade, injustiça, violência, escravidão, subordinação etc. Todas essas são formas de relações sociais que limitam a possibilidade da vida das pessoas em nome das virtudes da liberdade, da individualidade e da justiça. Por conseguinte, é necessário aceitar a inseparabilidade da luta política e intelectual. Sem o conhecimento de realidades específicas de poder e das aspirações, esperanças, medos e raivas reais de pessoas que vivem dentro dessas relações de poder, continuaremos a contar histórias ruins e perderemos a batalha, se não imediatamente, eventualmente. Vamos acabar, se bem, no que Néstor García Canclini chamou de "a vergonha da democracia", ou no que De Sousa Santos descreveu como uma sociologia de emergências sem uma sociologia de ausências ${ }^{3}$ (GROSSBERG, 2017, p. 27).

Desse modo, sem encerrar as pessoas em determinadas fronteiras, sem limitá-las ou delimitá-las, assegurando que as muralhas possam ser ultrapassadas, compreendendo, com Fanon (2008, p. 90), que "não se deve tentar fixar o homem, pois o seu destino é ser solto", será possível que das lutas negras participem os não-negros; que, nas lutas feministas, façam-se presentes aqueles que, biologicamente, estão configurados como masculinos; que os mastros das bandeiras coloridas sejam erguidos por todos, independentemente da orientação sexual; e que, por fim, a grande luta e a luta grande compreendam o reconhecimento, a valorização e o diálogo com o outro - seus modos de ser, de fazer, de compreender/aprender e de estar no mundo (não apenas navegar, mas sonhar também é preciso).

Por fim, como, aqui, somos movidos pelo objetivo de pensar as razões que subjazem e

\footnotetext{
${ }^{3}$ Tenemos que comprender cómo y por qué las sociedades continúan produciendo todo tipo de formas de inhumanidad, de inequidad, injusticia, violencia, esclavitud, subordinación, etc. Todas estas son formas de relaciones sociales que limitan la posibilidad de vida de la gente en nombre de las virtudes de la libertad, la individualidad y la justicia. Por lo tanto, es necesario aceptar la inseparabilidad de la lucha política e intelectual. Sin el conocimiento de realidades de poder específicas, de aspiraciones, esperanzas, miedos y rabias concretas de la gente viviendo dentro de estas relaciones de poder seguiremos contando malas historias y perdiendo la batalla, si no inmediatamente, eventualmente. Terminaremos, si nos va bien, en lo que Néstor García Canclini llamó "la vergüenza de la democracia", o en lo que De Sousa Santos describió como una sociología de las emergencias sin una sociología de las ausencias.
}

Periódico Horizontes - USF - Itatiba, SP - Brasil - e019034 
fundamentam as práticas curriculares excludentes (invisibilizadoras) - considerando a Educação Escolar Quilombola -, no presente artigo pontuamos, mesmo que com brevidade, alguns elementos que compõem o corpus (histórico, social e cultural) das semantizações e ressemantizações de quilombo e, logo a seguir, transitamos rapidamente pela seara da Educação Escolar Quilombola, considerando nossas próprias pesquisas e investigações outras realizadas por pesquisadores que se debruçam sobre a temática.

\section{Quilombo: lugar, não-lugar...}

De acordo com Kabengele Munanga (1995/1996), a palavra quilombo (forma aportuguesada de kilombo) é originária dos povos de origem bantu: "Sua presença e seu significado no Brasil têm a ver com alguns ramos desses povos bantu cujos membros foram trazidos e escravizados nesta terra. Trata-se dos grupos lunda, ovimbundu, mbundu, kongo, imbangala etc., cujos territórios se dividem entre Angola e Zaire"” (MUNANGA, 1995/1996, p.58). Dessarte, parece-nos bastante plausível depreender da afirmação de Munanga que, mesmo esses povos sendo oriundos de regiões diversas do continente negro, a resistência à escravização teria a língua como uma aliada fortíssima à sua organização. Com isso não queremos reduzir as imensas dificuldades, os obstáculos rochosos que se lhes apresentaram em terras receptoras (que vão desde o desconhecimento geográfico às torturas engenhosas diante de tentativas insurrecionais), mas apresentar um elemento facilitador às arquiteturas de fuga, vez que as línguas faladas por esses povos preservavam um radical comum. "O estudo de algumas palavras principais revelou a existência das mesmas raízes com o mesmo conteúdo entre esses povos" (MUNANGA, 1995/1996, p. 58).

Essa nossa conclusão parece ganhar certa substantividade quando observamos os dados (território brasileiro e povoamento) apresentados pelo Instituto Brasileiro de Geografia e Estatística (IBGE), os quais revelam o número estimado de desembarques de africanos no Brasil, por procedência regional, considerando os períodos de 1701 a 1810. Naquele período, Angola e Costa do Marfim, nessa ordem, foram as regiões que alimentaram o tráfico negreiro destinado

\footnotetext{
${ }^{4}$ Desde 1997, o Zaire adotou o nome de República Democrática do Congo, país da África Central.
} Periódico Horizontes - USF - Itatiba, SP - Brasil - e019034 
ao Brasil: "Chefes políticos e mercadores da África Centro-Ocidental (hoje região ocupada por Angola) forneceram a maior parte de escravos utilizados em toda América portuguesa" (IBGE, 2000).

De qualquer sorte, e ainda nos inspirando em Munanga (1995/1996), os quilombos representaram uma instituição política e militar, de cultura bantu, que se fez presente (nem sempre preservando esse nome) em todas as regiões onde a escravização do povo negro se efetivou. Convém, à vista disso, trazer à baila que as definições conferidas à organização "quilombo" (considerando os períodos Colonial, Imperial e República) e, em razão disso, aos seus agentes (quilombolas), guardam em si a relação quase embrionária entre fuga e resistência. Entretanto, as pesquisas de O'Dwyer (2002) demonstram a grande diversidade de possibilidades de formação de quilombos, que, obviamente, passavam pelos movimentos insurrecionais ou rebelados, mas, em todos os casos, "consistem em grupos que desenvolveram práticas cotidianas de resistência [nem sempre como sinônimo de conflito] na manutenção e reprodução de seus modos de vida característicos e na consolidação de um território próprio" (O'DWYER, 2002, p.19). Assim, outros modos de formação de quilombos podem ser apresentados: aquisição de terras mediante a compra por família de escravos alforriados; doação de terras, quando o impacto da queda do preço dos produtos, como algodão e cana-de-açúcar, foi tão grande que desembocou no desmonte de vários engenhos; heranças e indenizações.

De toda forma, nessas comunidades, juntavam-se negros e negras (mas não só!) de etnias distintas, e um modo híbrido (também a partir das práticas culturais incorporadas no novo habitat) de existir (de fazer, de aprender, de se comunicar e de se relacionar - de ser, enfim) ia paulatinamente sendo erigido. Essas práticas culturais híbridas singularizavam/singularizam esses grupos, conferindo-Ihes características que os delineiam, mas não os engessam.

Uma palavra a mais. Ainda no tocante a quilombo, o que, cremos, resulta do erguimento de uma nação a partir de substratos escravagistas, racistas e pigmentocráticos - esses últimos, precisamos esclarecer, são aqui compreendidos como "o privilégio da pele clara (light skin) em relação à escura (dark skin) no tocante às oportunidades de mobilidade social", como nos alerta Nascimento (2015, p. 01) -, gostaríamos de enfatizar mais um elemento. Noutro lugar, afirmamos, sob o lume de Michel Foucault (2013) e de Boaventura de Sousa Santos (2009), que "mesmo simbolizando as lutas políticas dos movimentos negros na contemporaneidade - ou 
talvez por isso mesmo -, quilombos e quilombolas são alocados, de acordo com o pensamento abissal moderno, 'do outro lado da linha' desse pensamento" (FRANÇA; MENDES; AGUIAR, 2017). Lá, buscávamos compreender os dispositivos que são convocados por um certo pensamento (hegemônico) abissal moderno que aloca quilombos e quilombolas em zona profundamente marcada pela dicotomia apropriação/violência, que "reconhece apenas o direito das coisas, sejam elas humanas ou não" (SANTOS, 2009, p.30). Cá, buscamos inserir nessas discussões a educação formal, considerando aquela prescrita pela Resolução CNE/CEB $n$. o 08/2012, que institui a Educação Escolar Quilombola, com o objetivo de pensar as razões que subjazem e fundamentam as práticas curriculares excludentes (invisibilizadoras). Lá e cá, pretendemos inserir nessa imensa caixa (foucaultiana) alguma ferramenta que contribua para o desvelamento dos dispositivos que alicerçam a construção do não-ser.

\section{Educação escolar quilombola, quando?}

A Lei de Diretrizes e Bases da Educação Nacional - LDB 9394/96 - (BRASIL, 1996) organiza a educação brasileira e, para tanto, a divide em níveis e modalidades. Dentre os níveis, constam a Educação Básica e o Ensino Superior; em relação às modalidades, esse dispositivo definiu, inicialmente, a Educação de Jovens e Adultos, a Educação Especial, a Educação Profissional e Tecnológica, a Educação do Campo, a Educação Escolar Indígena e a Educação a Distância. Nesse primeiro momento de vigência, que perdurou por um tempo significativo, a lei em epígrafe não estabeleceu uma modalidade que atendesse e atentasse para as comunidades quilombolas, ainda que elas existissem e representassem, como sublinha Arruti (2017, p. 116), os grupos "mais pobres dos mais pobres", e ainda que essa mesma legislação estabelecesse que "o ensino da História do Brasil deve levar em conta as contribuições das diferentes culturas e etnias para a formação do povo brasileiro, especialmente das matrizes indígena, africana e europeia" (BRASIL, 1996, Art. 36, § 4으, grifo nosso).

Antes de continuarmos nessa trajetória, de lutas e conquistas, que se fizeram necessárias ao alcance da oficialização da modalidade Educação Escolar Quilombola, gostaríamos de acrescentar, a partir do entendimento de Domingues (2007), a relevância atribuída à educação pelo povo negro, ao longo de sua história em terras brasileiras: 
Em São Paulo, apareceram o Clube 13 de Maio dos Homens Pretos (1902), o Centro Literário dos Homens de Cor (1903), a Sociedade Propugnadora 13 de Maio (1906), o Centro Cultural Henrique Dias (1908), a Sociedade União Cívica dos Homens de Cor (1915), a Associação Protetora dos Brasileiros Pretos (1917); no Rio de Janeiro, o Centro da Federação dos Homens de Cor; em Pelotas/RG, a Sociedade Progresso da Raça Africana (1891); em Lages/SC, o Centro Cívico Cruz e Souza (1918). Em São Paulo, a agremiação negra mais antiga desse período foi o Clube 28 de Setembro, constituído em 1897. As maiores delas foram o Grupo Dramático e Recreativo Kosmos e o Centro Cívico Palmares, fundados em 1908 e 1926, respectivamente (p. 103).

França (2013, p. 96) acrescenta que "de cunho assistencialista, cultural e/ou recreativo (mas sempre de resistência), as agremiações, associações ou agrupamentos reuniam um número significativo de negros e negras que buscavam, coletivamente, empoderar suas reivindicações e/ou assegurar a manifestação da cultura de seus ascendentes". Dentre as reivindicações, a educação do povo negro ${ }^{5}$ sempre estampou as bandeiras desfraldadas pelos movimentos negros (GONÇALVES; SILVA, 2000). E a luta exigiu continuidade.

Em 2003, com a instituição da Lei 10.639/2003, mais um passo em direção a reivindicações mais específicas foi desenhado. Segundo a legislação acima apresentada: "nos estabelecimentos de ensino fundamental e médio, oficiais e particulares, torna-se obrigatório o ensino sobre História e Cultura Afro-Brasileira" (BRASIL, 2003a, Art.26-A). E continua:

O conteúdo programático a que se refere o caput deste artigo incluirá o estudo da História da África e dos Africanos, a luta dos negros no Brasil, a cultura negra brasileira e o negro na formação da sociedade nacional, resgatando a contribuição do povo negro nas áreas social, econômica e política pertinentes à História do Brasil (BRASIL, 2003a, Art.26-A, §1ํ).

O artigo posterior acrescenta ainda que "os conteúdos referentes à História e Cultura Afro-Brasileira serão ministrados no âmbito de todo o currículo escolar, em especial nas áreas de Educação Artística e de Literatura e História Brasileiras" (Art.26-A, §2º), e o Artigo 79-B determina que o calendário escolar deverá incluir o dia 20 de novembro como "Dia Nacional da Consciência Negra" - uma homenagem ao líder quilombola Zumbi dos Palmares. Uma

\footnotetext{
${ }^{5}$ Consideramos povo negro os homens e as mulheres que preservam características físicas e/ou culturais aportadas nas ancestralidades africanas.
}

Periódico Horizontes - USF - Itatiba, SP - Brasil - e019034 
revolução? Talvez. Certo é que a Lei 10.639/2003, além dos alcances já elencados, reconhece, segundo entendemos, o racismo institucional e nega, por essa via, a presença de uma democracia racial no território nacional. Porém, ainda não assegura a Educação Escolar Quilombola.

A Resolução CNE/CP n.ำ01/2004, que “Institui Diretrizes Curriculares Nacionais para a Educação das Relações Étnico-Raciais e para o Ensino de História e Cultura Afro-Brasileira e Africana", ainda que não aborde diretamente a Educação Escolar Quilombola, contribui para o debate quando estabelece que o "Ensino de História e Cultura Afro-Brasileira e Africana tem por objetivo o reconhecimento e valorização da identidade, história e cultura dos afro-brasileiros, bem como a garantia de reconhecimento e igualdade de valorização das raízes africanas da nação brasileira [...]" (BRASIL, 2004a, Art.2을 §2). Desse modo, a referida resolução ressalta as contribuições históricas e culturais de base africana em caráter de igualdade ao lado das indígenas, europeias e asiáticas - o que colaboraria, em termos de Veiga-Neto (2003), para pensar/fazer o currículo e a cultura de forma plural, visto que não se pode pensar escola/educação sem pensar a pluralidade.

Há outros dispositivos legais significativos na resolução em espelho, como a possibilidade de estabelecimento de canais de comunicação entre os sistemas de ensino com grupos do Movimento Negro, elaboração de material didático e formação de professores para a educação de negros e negras, dentre outros. Mesmo assim, a Educação Escolar Quilombola como modalidade ainda não encontra concretude legal.

Para encurtar o caminho aqui delineado, registramos que somente dez anos após a promulgação da LDB 9394/96 há a publicação do documento “Orientações e Ações para a Educação das Relações Étnico-Raciais" (BRASIL, 2006), pelo Ministério da Educação (MEC), a partir da Secretaria de Educação Continuada, Alfabetização e Diversidade (SECAD), que aborda a Educação Quilombola (com essa nomenclatura) entendendo que essa modalidade de educação deve ser ofertada por escolas localizadas em comunidades remanescentes de quilombos ou por outras unidades de ensino que, mesmo não circunscritas a comunidades quilombolas, recebem estudantes delas oriundos.

Outros instrumentos oficiais/legais vão, a partir disso, abordar a temática. É o caso, por exemplo, da Resolução CNE/CEB no 07/2010, "que fixa Diretrizes Curriculares Nacionais para o Periódico Horizontes - USF - Itatiba, SP - Brasil - e019034 
Ensino Fundamental de 9 anos", e do documento produzido pela Conferência Nacional de Educação de 2010 (CONAE/2010), o qual, seguindo Arruti,

[...] tinha como uma das novidades mais notáveis a introdução de um capítulo sobre educação quilombola. Nele, estava previsto o direito à preservação das manifestações culturais dessas comunidades, da sustentabilidade de seu território tradicional, da observação de uma alimentação e de uma infraestrutura escolar que respeitem sua cultura e sua relação com o meio ambiente, assim como a formação diferenciada dos professores destas escolas, a criação de um programa de licenciatura quilombola, a elaboração de materiais didático-pedagógicos específicos e, no campo da gestão, a adoção de mecanismos que garantam a participação de representantes quilombolas na composição dos conselhos referentes à educação (2017, p. 116).

É, entretanto, somente em 20 de novembro de 2012, por via da Resolução CNE/CEB n.으 08/2012, que são definidas as “Diretrizes Curriculares Nacionais para a Educação Escolar Quilombola na Educação Básica". Do ponto de vista do atendimento às reivindicações, e considerando, no lócus legal, o reconhecimento das características singulares desses territórios (no que concerne aos modos de existir - e de ser) e ainda lembrando que já havia uma modalidade específica para a educação escolar dos povos indígenas, a conquista é substantiva. Mas, e no cotidiano dessas populações (quilombolas), como essa educação tem se materializado? Como os currículos, ainda que territórios contestados (SILVA, 2003), vêm sendo mobilizados e efetivados no dia a dia dos quilombos? Há visibilização, pela e na escola, das práticas culturais de educandos e educandas que tomam assento nos bancos escolares? Para responder às questões elencadas pensamos ser necessário voltar à resolução supracitada e conferir o que nela se encontra disposto e o que desvelam as pesquisas realizadas em comunidades quilombolas brasileiras, tendo a educação como mote.

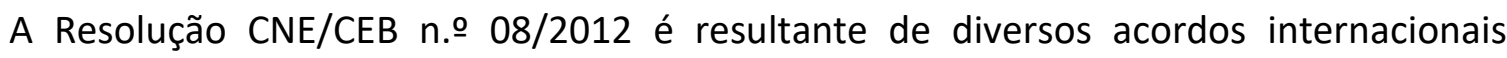
(exemplo: a Convenção 169 da Organização Internacional do Trabalho/OIT sobre Povos Indígenas e Tribais, promulgada no Brasil, por meio do Decreto no 5.051, de 19 de abril de 2004 (BRASIL, 2004b) e de instrumentos de ordem legal implementados pelo Estado brasileiro, como é o caso da Constituição Federal de 1988 (no seu artigo 50, inciso XLII, dos Direitos e Garantias Fundamentais, e no seu artigo 68 do Ato das Disposições Constitucionais Transitórias). É também (pode-se afirmar) um coroamento das lutas históricas dos movimentos negros, lato ou stricto

$$
\text { Periódico Horizontes - USF - Itatiba, SP - Brasil - e019034 }
$$


sensu, haja vista que a educação e a valorização de suas práticas culturais sempre bordaram as bandeiras de luta desses movimentos.

De acordo com a resolução em destaque, a Educação Escolar Quilombola deve ser ofertada por escolas localizadas em territórios remanescentes de quilombos e também por aquelas que, mesmo neles não localizadas, atendem a crianças, jovens e adultos deles oriundos (BRASIL, 2012, Art.1ㅇ, IV), sejam essas comunidades rurais ou urbanas. A norma citada define ainda que essa modalidade deve ser organizada tendo como substrato: a) a memória coletiva; b) as línguas reminiscentes; c) os marcos civilizatórios; d) as práticas culturais; e) as tecnologias e formas de produção do trabalho; f) os acervos e repertórios orais; g) os festejos, usos, tradições e demais elementos que conformam o patrimônio cultural das comunidades quilombolas de todo o país; h) a territorialidade. É, indubitavelmente, do ponto de vista da legislação, um avanço relevante. Cada um desses oito elementos, que devem fundamentar, informar e alimentar o ensino, traz uma carga histórica, cultural e social, portanto visceralmente imbricada nos processos de subjetivação e singularização dos sujeitos, de significados de difícil mensuração. Com isso, não estamos estruturando obstáculos a essa modalidade de ensino; apenas pretendemos destacar a força de cada um desses elementos e a necessidade de implantação e/ou implementação de estratégias que lhes assegurem corporeidade.

Mas, isso ainda não é tudo. Todas as etapas e modalidades (Educação Infantil, Ensino Fundamental, Ensino Médio, Educação do Campo, Educação Especial, Educação Profissional e Técnica de Nível Médio, Educação de Jovens e Adultos, Educação a Distância), caso envolvam quilombolas, devem efetivar-se a partir da Educação Escolar Quilombola. Consequentemente, todas as disciplinas e seus respectivos professores e professoras deverão atuar com práticas (pedagógicas) que se encontrem em sintonia com a modalidade em questão. Os currículos dessas escolas (que possuem alunos quilombolas), de acordo com o Artigo 34 (BRASIL, 2012), "devem ser construídos a partir dos valores e interesses das comunidades quilombolas em relação aos seus projetos de sociedade e de escola, definidos nos projetos político-pedagógicos" (§ 1을 e também devem "considerar, na sua organização e prática, os contextos socioculturais, regionais e territoriais das comunidades quilombolas em seus projetos de Educação Escolar Quilombola" (§ 2ㅇ).

Como se vê, trata-se de empreitada não hercúlea, porque é possível a humanos (e não Periódico Horizontes - USF - Itatiba, SP - Brasil - e019034 
tão somente a filhos de deuses), mas gigantesca. E, para que seja efetivada, torna-se necessária e urgente a consolidação de políticas que impeçam a morte da letra. Ou seja: há um arcabouço legal e histórico, tanto no plano internacional quanto nacional, que ferramenta os sujeitos e as instituições no que concerne à garantia do direito; contudo, a força da lei precisa converter-se em ações concretas capazes de viabilizá-la e vitalizá-la, caso contrário - e esse receio nos acompanha -, ter-se-á mais um conjunto de elementos que serve de estamparia a um tecido corroído. Mas, então, o que fotografam as pesquisas, que se desdobram no cotidiano das escolas e na realidade dos sujeitos que as constituem?

Investigações realizadas em escolas localizadas em quilombos revelam que a educação formal nelas oferecida não assegura a permanência e o sucesso do aluno, ou por precariedade na infraestrutura, ou por carências na formação dos professores, ou por ausência de diálogos com a contextura sociocultural (LOPES, 2012; MAROUN, 2013; TAVEIRA, 2013), ou por descontinuidades das políticas públicas (SOARES, 2012), ou por conta do "velho preconceito contra os descendentes de escravos, isto é, contra os quilombolas" (MOROUN, 2013, p.194).

Maria Walburga Santos (2010, p. 304), em pesquisa realizada na comunidade quilombola Bombas (Iporanga - São Paulo), diagnostica que "na escola [quilombola] os saberes do grupo, da terra têm pouco valor. É lugar para ficar sentado, prestando atenção e aprendendo os conteúdos formais dos livros [...]", os quais, inclusive, são descontextualizados e desprovidos de sentidos para meninos e meninas.

Em Sergipe, as pesquisas de Glezia Kelly Costa Santos (2011), realizadas em comunidades quilombolas do campo, revelam a quase inexistência de políticas públicas relacionadas à educação e mostram a fragilidade pedagógica dos docentes para atuarem em escolas quilombolas, cujas razões se encontram no processo de formação dos educadores.

O Grupo de Estudos e Pesquisas Identidades e Alteridades: Diferenças e Desigualdades na Educação (GEPIADDE), da Universidade Federal de Sergipe (UFS), através do projeto Saberes e Práticas de Matemática e Ciências nos Anos Iniciais do Ensino Fundamental, coordenado pela Prof.a Dr. a Maria Batista Lima, tem desenvolvido na microrregião do agreste sergipano e também em quilombos, desde 2010, pesquisas que buscam detectar a relação que os estudantes estabelecem com os saberes das disciplinas (presentes no título do projeto) e ainda se são estabelecidos diálogos entre as referidas disciplinas e as africanidades. As conclusões revelam a 
inexistência de tais diálogos e um desconhecimento significativo dos gestores e professores, das escolas, referente às legislações que estabelecem a obrigatoriedade do ensino da história e cultura africana e afro-brasileira, mesmo naquelas plantadas em quilombos.

As pesquisas realizadas por França (2013), no quilombo Mussuca, em 2012, objetivando analisar as percepções sobre os saberes matemáticos apresentadas por estudantes do 50 ano do Ensino Fundamental da comunidade quilombola e a relação estabelecida por esses estudantes, professoras polivalentes, gestores da escola municipal, bem como pelos membros da comunidade em questão com esses mesmos saberes e com a relação deles com as africanidades, revelaram que: a) a proposta pedagógica estabelece um diálogo bastante frágil com a contextura sociocultural do quilombo; b) as legislações e/ou instrumentos que tratam da pluralidade cultural, do ensino de história e cultura africana e afro-brasileira e da educação para as relações étnico-raciais são desconhecidos pela maioria absoluta dos que fazem a escola; c) como consequência, as temáticas supracitadas não aparecem ou aparecem timidamente na ação pedagógica da unidade de ensino. Isso posto, as ponderações de Arruti nos parecem cirúrgicas:

[...] é preciso considerar que aquilo que genericamente é chamado de "escola quilombola" (inclusive em documentos oficiais) e que, dessa forma, leva-nos a imaginar uma situação escolar diferenciada, na verdade corresponde ao que, no Censo Escolar, é identificado, de forma muito mais prosaica, como "escolas em áreas de quilombo". Ou seja, essas escolas são "quilombolas" apenas na medida em que estão situadas em terras que são assim identificadas. Isso ocorre por uma reclassificação das escolas já existentes - possível depois da introdução desta categoria no censo escolar do Instituto Nacional de Estudos e Pesquisas Educacionais Anísio Teixeira (INEP) em 2004 -, sem que isso implique a existência de qualquer diferenciação na sua forma física, nos métodos pedagógicos, na sua gestão, na composição e formação dos seus professores, nos materiais didáticos utilizados ou mesmo no tipo de atenção dada pelo corpo docente a temas fundamentais nesse contexto, como as relações raciais e a própria questão dos quilombos (ARRUTI, 2013, p. 119).

Talvez, reste-nos, a partir desse cenário, buscar compreender as razões que se esgueiram por entre as tentativas de silenciamento ou de apagamento das marcas dos "pobres dos mais pobres". Nessa seara, tenderíamos a pinçar razões que habitariam na falta de políticas públicas específicas para essa modalidade de educação, na inexistência (ou quase isso) de formação inicial ou continuada de professores e professoras, nas construções históricas que se pautam numa 
cosmovisão europeia e no racismo que se imiscui por entre as células do tecido social brasileiro. Não obstante, pensamos que há uma causa primeira da qual são filhas essas razões apontadas. Boaventura de Sousa Santos (2009, p. 26) assim se expõe:

\footnotetext{
Esta negação radical de co-presença fundamenta a afirmação da diferença radical que, deste lado da linha, separa o verdadeiro do falso, o legal do ilegal. O outro lado da linha compreende uma vasta gama de experiências desperdiçadas, tornadas invisíveis, tal como os seus autores, e sem uma localização fixa.
}

São, consequentemente, essas tentativas de impedimento da co-presença, de uma copresença que precisa ser radical - significando que práticas e agentes de ambos os lados da linha são contemporâneos em termos igualitários (SANTOS, B., 2009) - que justificam a inexistência de políticas (em sentido amplo) e que, por sua vez, impedem a implementação do instituto legal e da garantia dos direitos "dos pobres dos mais pobres". É ainda esse sociólogo que nos lembra que não pode haver justiça social global sem justiça cognitiva global e que o estabelecimento de um estatuto epistemológico tem como objetivo definir os lugares do conhecimento e de quem tem direito à fala.

Parece que, nesse entendimento esboçado pelo sociólogo português, seja possível alocar os quilombos e os quilombolas. Trindade (2007) grita a plenos pulmões que "Eu sei, eu sei que sou um pedaço d'África / pendurado na noite do meu povo. / Trago em meu corpo a marca das chibatas / como rubros degraus feitos de carne / pelos quais as carretas do progresso / iam buscar as brenhas do futuro". Todos os brasileiros e brasileiras são "pedaços d'África", todos os quilombolas trazem no "corpo a marca das chibatas / como rubros degraus feitos de carne" e talvez por isso mesmo devam, à guisa do que ocorreu com os documentos oficiais que fotogravavam a escravização dos seus ancestrais, ter seus feitos apagados, corpos apagados, seus espíritos apagados.

\section{Considerações finais}

Pois bem, chegou o momento de encostar a porta, não de cerrá-la, de chaveá-la, apenas encostá-la contra os batentes, deixá-la ao sabor dos ventos, dos tempos, das forças explicáveis 
e inexplicáveis, visíveis e invisíveis; apenas encostá-la sem força para facilitar a abertura, outras aberturas, aberturas outras - seu escancaramento: é preciso facilitar o ingresso de outros e outras, o olhar de outros e outras -, também os desvios, a cegueira em relação à porta ou ao que nela há; ou ao que, através dela, enxerga-se ou não se vê.

Para tanto, seguraremos inicialmente a mão de Grossberg para pensarmos, juntos, a imprescindibilidade do contexto na construção da proposta pedagógica, dos currículos, dos fazeres docentes.

Trata-se de ver o contexto tanto como o objeto da análise como a força que determina nossa análise. Compreender o contexto como um campo multidimensional de relações é do que se trata os estudos culturais; não se trata de entender a cultura, mas de entender o contexto com a cultura como um elemento absolutamente vital e, como é para muitos, a forma pela qual entramos no contexto. Assim, não devemos pensar no contexto como uma entidade definida, estável, geograficamente e temporariamente definida, nem como um caos desordenado e aleatório. Em vez disso, devemos entender o contexto como sendo alternativo e ativo, como organizado e organizador ${ }^{6}$. (GROSSBERG, 2017, p. 29).

O texto de Grossberg refere-se à prática dos estudos culturais e considera as experiências e os ensinamentos que ele acessou à conta de sua convivência com Stuart Hall. Isso não inviabiliza, sem embargo, o transporte dos entendimentos do estudioso estadunidense para a prática educacional. Ao contrário, pensar a contextura sociocultural e tê-la como substância para pensar/fazer educação não é tão somente facilitar a aprendizagem dos estudantes ou respeitar a comunidade (imediata) onde a escola se encontra implantada; é bem mais que isso: é garantir o diálogo e a presença da diferença e dos diferentes no chão da escola e dos sistemas de ensino - isso se essa prática contextualizada se efetiva em todos os processos educacionais e pedagógicos de modo a assegurar-lhes participação democrática e ativa.

Todavia, quando advogamos um currículo situado, contextualizado, não o delineamos a

\footnotetext{
${ }^{6}$ Se trata de ver el contexto tanto como el objeto del análisis como la fuerza que determina nuestro análisis. Entender el contexto como un campo multidimensional de relaciones, es de lo que se trata los estudios culturales; no se trata de entender la cultura sino de comprender el contexto con la cultura como un elemento absolutamente vital y, como lo es para muchos, la manera por la que entramos al contexto. Así, no debemos pensar el contexto como uma entidad fija, estable, geográfica y temporalmente pre definida, ni tampoco como un caos desordenado y aleatorio. En su lugar, debemos entender el contexto como cambiante y activo, como organizado y organizador.
}

Periódico Horizontes - USF - Itatiba, SP - Brasil - e019034 
partir de fronteiras que Ihe sirvam de camisa de força: o contexto sociocultural (imediato) é fundamental, mas não deve servir de limites à ação educacional e/ou à ação pedagógica. A escola precisa ser maior do que isso, pois os estudantes e os seus professores são maiores do que isso - repetindo Fanon (2008, p. 90), "não se deve tentar fixar o homem, pois o seu destino é ser solto". E também os grupos, as comunidades, as sociedades são atravessadas por modos outros de ser, de compreender, de interagir. O hibridismo está aqui, está ali, está acolá, em trocas de hoje, de ontem, de amanhã e de sempre. São trocas que fazemos, que nos fazem. Normalmente, concretizam-se assimetricamente, verticalmente, impositivamente, e isso deve, sim, converterse em preocupação, em razão para a mobilização; nunca, no entanto, com o propósito de impedimento, de isolamento, de pureza. O contexto resulta de contextos, e o que nele há de singular é o modo como os empréstimos são semantizados, ressemantizados, criados e recriados.

O que aqui estamos querendo pontuar é que a Educação Escolar Quilombola, orientandose pelos dispositivos legais já existentes, precisa se corporificar. Há que se garantir nas escolas quilombolas (aquelas localizadas em comunidades remanescentes de quilombos) e também nas que não o são, mas que recebem educandos e educandas quilombolas, a implantação e implementação da modalidade em foco porque, como nos parece, esse é um passo necessário à co-presença, à ecologia de saberes, em termos de Boaventura de Sousa Santos (2009). É também caminho para a valorização da tradição - da tradição viva, na voz de Hampaté Bâ (2010). Conforme esse pensador, "a tradição africana [...] concebe a fala como um dom de Deus. Ela é ao mesmo tempo divina no sentido descendente e sagrada no sentido ascendente" (HAMPATÉ BÂ, 2010, p.182). A fala humana é também criação, preservação, transformação. $E$, no sentido da conservação dos saberes tradicionais, ela se encontra na comunidade, notadamente nos corpos dos anciãos, independentemente de serem eles alfabetizados ou não ${ }^{7}$. Além disso, cremos que, nas comunidades quilombolas, há tradições (práticas culturais, ainda que elas tenham recebido contribuições outras) que precisam ser conhecidas, reconhecidas e valorizadas pela escola (quilombola ou não).

\footnotetext{
${ }^{7}$ Recorremos a essa expressão, que consideramos infeliz, vez que os registros dos conhecimentos são efetuados independentemente da escrita alfabética, apenas para pontuar o domínio ou não, por parte das pessoas, dessa modalidade de registro.
} 
Ainda assim, considerando, na esteira de Mbembe (2014, p.305, grifo nossos), que a "construção do comum é inseparável da reinvenção da comunidade", advogamos que essa comunidade precisa ser sempre (e cada vez mais) alargada e os diferentes saberes, socializados - ainda que as tensões existam e persistam. Não estamos pensando aqui na implementação de uma escola monocultural. Não, longe disso. Pensamos, sim, agora tentando segurar as mãos de Mantoan e Lima (2017, p.824), numa "abertura da escola para todo e qualquer estudante!", o que implicaria o reconhecimento da diferença, que se multiplica sempre (em um e em todos) como elemento constitutivo de estudantes, de professores, das pessoas e de suas práticas.

Enfim, a Educação Escolar Quilombola precisa ser reivindicada e defendida, mas esse não pode ser o seu devir.

\section{Referências}

ARRUTI, J. M. Conceitos, normas e números: uma introdução à Educação Escolar Quilombola. Revista Contemporânea de Educação, vol.12, n.23, jan/abr de 2017. Disponível em: file://C:/Users/evani/Desktop/Uma\%20Introdução\%20à\%20Educação\%20 Escolar\%20Quilombola_ARRUTI\%20-\%20Copiar.pdf. Acesso em: 13 nov. 2017.

BRASIL. Lei $n^{\circ}$ 9.394, 20 de dezembro de 1996. Institui as Diretrizes e Bases da Educação Nacional. Disponível em: http://portal.mec.gov.br/arquivos/pdf/ldb.pdf. Acesso em: 26 jun. 2016.

BRASIL. Lei 10.639/2003, de 09 de janeiro de 2003a. Altera a Lei no 9.394, de 20 de dezembro de 1996, que estabelece as diretrizes e bases da educação nacional, para incluir no currículo oficial da Rede de Ensino a obrigatoriedade da temática "História e Cultura Afro-Brasileira", e dá outras providências. Disponível em:

http://www.planalto.gov.br/ccivil_03/leis/2003/L10.639.htm. Acesso em: 01 nov. 2017.

BRASIL. Decreto 4.887, de 20 de novembro de 2003b. Regulamenta o procedimento para identificação, reconhecimento, delimitação, demarcação e titulação das terras ocupadas por remanescentes das comunidades dos quilombos de que trata o art. 68 do Ato das Disposições Constitucionais Transitórias. Disponível em: http://www.planalto.gov.br/ccivil_03/decreto/2003/d4887.htm. Acesso em 13 nov. 2017.

BRASIL. Resolução no 01/2004a. Institui as Diretrizes Curriculares Nacionais para a Educação das Relações Étnico-Raciais e para o Ensino de História e Cultura Afro-Brasileira e Africana. Diário Oficial da União, Brasília, DF, 22 de junho de 2004, Seção 1, p.11. 
BRASIL. Decreto n. 0 5.051, de 09 de abril de 2004b. Promulga a Convenção no 169 da Organização Internacional do Trabalho/OIT sobre Povos Indígenas e Tribais. Disponível em: http://www.planalto.gov.br/ccivil_03/_ato2004-2006/2004/decreto/d5051.htm. Acesso em: 25 de abr. 2018.

BRASIL. Ministério da Educação/ Secretaria de Educação Continuada, Alfabetização e Diversidade. Orientações e ações para Educação das Relações Étnico-Raciais. Brasília: SECAD, 2006. Disponível em: http://portal.mec.gov.br/dmdocuments/orientacoes_etnicoraciais.pdf. Acesso em: 14 nov. 2017.

BRASIL. Conselho Nacional de Educação/ Câmera de Educação Básica. Resolução CNE/CEB no 07/2010. Fixa Diretrizes Curriculares Nacionais para o Ensino Fundamental de 09 Anos. Disponível em: http://portal.mec.gov.br/dmdocuments/rceb007_10.pdf. Acesso em: 28 de mar. 2018.

BRASIL. Conselho Nacional de Educação/ Câmera de Educação Básica. Resolução CNE/CEB no 08/2012, de 20 de novembro de 2012. Institui a Educação Escolar Quilombola Disponível em: http://portal.mec.gov.br/index.php?option=com_docman\&view=download\&alias=11963rceb008-12-pdf\&category_slug=novembro-2012-pdf\&Itemid=30192. Acesso em: 23 nov. 2017.

BRASIL. [Constituição (1988)] Constituição da República Federativa do Brasil. Brasília: Supremo Tribunal Federal. Secretaria de Documentação, [2017]. Disponível em:

http://www.stf.jus.br/arquivo/cms/legislacaoConstituicao/anexo/CF.pdf. Acesso em: 15 nov. 2017.

DOMINGUES, P. Movimento negro brasileiro: alguns apontamentos históricos. Tempo [online], vol.12, n.23, 2007. ISSN 1413-7704. Disponível em:

http://www.scielo.br/pdf/tem/v12n23/v12n23a07.pdf. Acesso em: 15 nov. 2017.

FANON, F. Pele negra, máscaras brancas. Salvador: EDUFBA, 2008.

FOUCAULT, M. De espaços outros. Estudos Avançados, vol.27, n.79, p.113-122, 2013. ISSN 0103-4014. Disponível em: http://www.scielo.br/pdf/ea/v27n79/v27n79a08.pdf>. Acesso em 24 out. 2017.

FRANÇA, E. T. Escola e cotidiano: um estudo das percepções matemáticas da comunidade quilombola Mussuca em Sergipe. 2013. 259f. Dissertação de (Mestrado em Ensino de Ciências e Matemática) - Universidade Federal de Sergipe, São Cristóvão, 2013.

FRANÇA, E. T.; MENDES, J. R.; AGUIAR, J. A. Alocação dos quilombos e dos quilombolas no espaço/tempo do pensamento abissal: reflexões para manutenção/fortalecimento da resistência. In: XI ENCONTRO INTERNACIONAL: EDUCAÇÃO E CONTEMPORANEIDADE, 2017, São Cristóvão. Anais[...], São Cristóvão: Universidade Federal de Sergipe, 2017, v.11, p.01-25. Disponível em:

https://ri.ufs.br/bitstream/riufs/8980/15/Alocacao_dos_quilombos_e_dos_quilombolas_no_es pacotempo_do_pensamento.pdf. Acesso em: 22 maio 2018. 
GALLO, S. Sob o signo da diferença: em torno de uma educação para a singularidade. In: SILVEIRA, R. M. H. Cultura, poder e educação: um debate sobre estudos culturais em educação. Canoas: ULBRA, 2005, p.213-223.

GONÇALVES, L. A. O.; SILVA, P. B. G. Movimento negro e educação. Revista Brasileira de Educação, n.15, p.134-158, 2005.

GROSSBERG, L. Stuart Hall: diez lecciones para los estudios culturales. Intervenciones em Estudios Culturales, v.4, p.25-37, 2017. Disponível em: https://intervencioneseecc.files. wordpress.com/2017/07/n4_art02_grossberg.pdf. Acesso em:10 nov. 2017.

HAMPATÉ BÂ, A. A tradição viva. In: UNESCO/MEC/UFSCar. História geral da África I metodologia e pré-história da África. Brasília: UNESCO, 2010, p.168-212. Disponível em: http://unesdoc.unesco.org/images/0019/001902/190249por.pdf. Acesso em: 15 nov. 2017.

INSTITUTO BRASILEIRO DE GEOGRAFIA E ESTATÍSTICA - IBGE. Território brasileiro e povoamento, 2000. Disponível em: Disponível em: https://brasil500anos.ibge.gov.br/territoriobrasileiro-e-povoamento/negros/regioes-de-origem-dos-escravos-negros.html. Acesso em: 12 de novembro de 2017.

LOPES, D. L. Rodas de conversa e educação escolar quilombola: arte do falar saber fazer - o Programa Brasil Quilombola em Restinga Seca/RS. 2012. 252f. Tese (Doutorado em Educação) Universidade Federal do Rio Grande do Sul, 2012.

MANTOAN, M. T. E.; LIMA, N. S. T. Notas sobre inclusão, escola e diferença. Educação Temática Digital, Campinas, v.19, n.4, p.824-832, out./dez.2017. Disponível em: https://periodicos.sbu.unicamp.br/ojs/index.php/etd/article/view/8646274. Acesso em: 15 nov. 2017.

MAROUN, K. Jogo e educação: a construção de uma identidade quilombola a partir de saberes étnico-culturais do corpo. 2013. 210. Tese (Doutorado em Educação) - Pontifícia Universidade Católica do Rio de Janeiro, Rio de Janeiro, 2013.

MBEMBE, A. Crítica da razão negra. Lisboa: Antígona, 2014.

MUNANGA, K. Origem e história do quilombo na África. Revista USP, São Paulo, v.28, p.56-63, dez./fev. 1995/1996.

NASCIMENTO, G. X. C. Os perigos dos negros brancos: cultura mulata, classe e beleza eugênica no pós-emancipação (EUA, 1900-1920). Revista Brasileira de História, São Paulo, v.35, n.69, p.155-176, 2015. Disponível em: http://dx.doi.org/10.1590/1806-93472015v35n69008. Acesso em: 13 nov. 2017.

O'DWYER, E. C. Os quilombos e a prática profissional dos antropólogos. In: O’DWYER, E. C. 
Quilombo: identidade étnica e territorialidade. Rio de Janeiro: Editora FGV, 2002, p.13-42. Disponível em: http://www.abant.org.br/conteudo/livros/Quilombos.pdf. Acesso em: 01 nov. 2017.

SANTOS, B. S. Para além do pensamento abissal: das linhas globais a uma ecologia dos saberes. In: SANTOS, B. S.; MENESES, M. P. (Org.). Epistemologias do sul. Coimbra: Edições Almedina S.A., 2009, p.23-72.

SANTOS, M. W. Saberes da terra: o lúdico em Bombas, uma comunidade quilombola (estudo de caso etnográfico). 2010. 321f. Tese (Doutorado em Educação) - Universidade de São Paulo, São Paulo, 2010.

SANTOS, G. K. C. As comunidades quilombolas do campo em Sergipe e os desafios da formação docente. 2011. 138f. Dissertação (Mestrado em Educação) - Universidade Federal de Sergipe, São Cristóvão, 2011.

SILVA, T. T. Documentos de identidade: uma introdução às teorias de currículo. São Paulo: Autêntica, 2003.

SOARES, E. G. Educação escolar quilombola: quando a política pública diferenciada é diferente. 2012. 131f. Tese (Doutorado em Educação) - Universidade Federal do Paraná, Curitiba, 2012.

TAVEIRA, A. C. F. Comunidade remanescente quilombola Kalunga: direito à educação como expressão de cidadania no Ensino Fundamental. 2013. 284f. Tese (Doutorado em Educação) Pontifícia Universidade Católica de Goiás, Goiânia, 2013.

TRINDADE, S. Poemas antológicos. São Paulo: Nova Alexandrina, 2007. Disponível em: http://www.elfikurten.com.br/2015/06/solano-trindade.html. Acesso em: 22 de maio de 2018.

VEIGA-NETO, A. Cultura, culturas e educação. Revista Brasileira de Educação, n.23, 2003. Disponível em: http://www.scielo.br/pdf/rbedu/n23/n23a01. Acesso em: 13 no. 2017.

Recebido em maio de 2018.

Aprovado em dezembro de 2018. 